\title{
A MULTI-MANNED PARALLEL TWO-SIDED ASSEMBLY LINE BALANCING WITH TOOL SHARING APPROACH- A COMPANY CASE STUDY SOLVED BY EXACT SOLUTION APPROACH
}

\author{
ASHISH YADAV \& SUNIL AGRAWAL \\ Department of Mechanical Engineering, PDPM Indian Institute of Information \\ Technology Design and Manufacturing, Jabalpur, India
}

\begin{abstract}
Purpose- The main aim of this paper is to develop a new mathematical model for the multi-manned parallel two-sided assembly line balancing problem (MPTALBP) generally occur in plants producing large-sized high-volume products such as buses or trucks.

Methodology-In this paper, the proposed mathematical model is applied to solve case study of multimanned parallel two-sided assembly line balancing problem to minimizing the total idle time and reduce the cost associated with tools in mated stations of an assembly line. The proposed mathematical model is solved using a branch and bound algorithm on lingo 17 solvers.

Findings- Based on the computational result, it can be seen that less number of workstations are utilized as compared to the theoretical minimum number of workstations with a shared tools approach that reduces space as well as the cost of tools.

Practical implications- Since the problem is well known as np-hard problem a company case study problem is solved and the result of the study can be beneficial for the automobile industry to reduce tool cost and overall cost by tools sharing approach.

Originality- On the basis of this literature review paper is first to address multi-manned parallel two-sided assembly line balancing problem using the exact solution approach.

KEYWORDS: Multi-Manned Parallel Two-Sided Assembly Line Balancing Problem, Mathematical Model, Case Study Problem, Tool Sharing \& Lingo -17 Solver
\end{abstract}

Received: Dec 24, 2018; Accepted: Jan 14, 2019; Published: Feb 05, 2019; Paper Id.: IJMPERDAPR20195

\section{INTRODUCTION}

An assembly line is a chronological organization of workstations around a conveyor belt or material handling system on which, after a cycle time, semi-finished products move from one station to their successive station and parts are assembled consecutively on it by satisfying specific constraints until the final assembly is produced. At the last station, the product is completed and then it leaves the line.

Generally two-sided assembly lines operating direction of the assembly tasks will be carried out on the similar product in parallel at both the left and right sides of the assembly lines. Because of this both sides of the line tasks will have extra operating direction restrictions. The directions are the left side $(\mathrm{L})$, the right side $(\mathrm{R})$, and 
either side (E) (Ozcan U, 2010; Chiang W-C et al., 2015).

Multi-manned parallel two-sided assembly line balancing problems (MPTALBP) are a new type of assembly line balancing problems where there are the chances of assigning additional one operator to each workstation as per the product features. MPTALBP typically happen in industries with big size and large volume of products, for example, automotive industry where the size of the product is large to employ the multi-manned assembly line configuration.

A MPTALBP has the substantial advantage such as it increases compactness on each workstation and reduces idle time, reduces the length of the assembly line, Reduces the cost of tools and fixtures, the material handling, Reduces the amount of throughput time, which increases production rate, worker movement, and setup time, possibility of completion of work increases when two or more operators work together on a single workstation.

\section{LITERATURE REVIEW}

Table 1: Overview of Literature on Multi-Manned Parallel Two Sided Assembly Line Balancing

\begin{tabular}{|c|c|c|}
\hline Name of Author & Objective(s) & Method(s) Used \\
\hline Dimitriadis et al.(2006) & $\begin{array}{ll}- & \text { Space utilization improvement } \\
\text { - } & \text { Minimization of idle time }\end{array}$ & Two-level heuristic procedure \\
\hline \multirow{2}{*}{ Fattahi et al.(2011) } & \multirow{2}{*}{$\begin{array}{l}\text { Minimization of workers. } \\
\text { Minimization of workstation. }\end{array}$} & Mixed integer programming \\
\hline & & Ant colony algorithm \\
\hline Qian et al.(2011) & Minimization of workers. & Genetic algorithm \\
\hline Roshani et al.(2013) & $\begin{array}{l}\text { Maximization of Line efficiency. } \\
\text { Minimization of Line length. } \\
\text { Minimization of smoothness index. }\end{array}$ & Simulated annealing algorithm \\
\hline \multirow{2}{*}{ Kellegoz et al.(2014) } & \multirow{2}{*}{ Minimization of workers. } & Constructive heuristic \\
\hline & & Genetic algorithm \\
\hline Roshani et al.(2015) & Minimization of cost. & Mixed integer programming \\
\hline Roshani et al.(2015) & Minimization of cycle time & Simulated annealing algorithm \\
\hline Yilmaz et al.(2015) & $\begin{array}{l}\text { Minimization of workers. } \\
\text { Minimization of workstation. } \\
\text { Minimization of idle time }\end{array}$ & Mixed integer programming \\
\hline Kucukkocet al.(2015) & Minimization of workstation. & Genetic algorithm \\
\hline \multirow{2}{*}{ Kellegoz et al.(2016) } & \multirow{2}{*}{$\begin{array}{ll}- & \text { Minimization of workers. } \\
\text { - } & \text { Minimization of workstation. }\end{array}$} & Mixed integer programming \\
\hline & & Gantt based heuristic \\
\hline Chen.(2017) & $\begin{array}{ll}\text { - } & \text { Minimization of workers. } \\
\text { - } & \text { Minimization of workstation. }\end{array}$ & Hybrid heuristic \\
\hline Chen.(2018) & Minimization of resources. & Simulated annealing algorithm \\
\hline
\end{tabular}

Although researchers have focused on multi-manned assembly line balancing problems but, the literature review suggests that very limited number of researchers focus on the multi-manned parallel two-sided assembly line balancing problem (MPTALB). MPTALB problems with the objective of minimizing workstations and idle time are very crucial in a number of industries.

This article mainly presents following contributions to the research field:

- A Mathematical Model of multi-manned parallel two-sided assembly line balancing problem is proposed with tool sharing approach to reduce cost of tool in assembly line.

- The proposed mathematical model is tested on an industrial problemand is solved using Lingo -17 solver to obtain 
- The results of case study problem are compared with the results ofthe theoretical minimum number of workstations. From this study, it is observed that the workstation and idle time are reduced.

- The rest of the paper is organized as follows: MPTALBP mathematical model is given in section 3 with objectives, assumptions and constraints. Section 4 illustrates a case study example problem and computational results. Conclusions and future work are presented in section 5.

\section{MATHEMATICAL FORMULATION}

\subsection{Overview}

The main objective of the proposed model is to assign the set of tasks to the multi-manned Parallel two-sided assembly line balancing with tool sharing so that requirement of tools associated with the system is minimized.

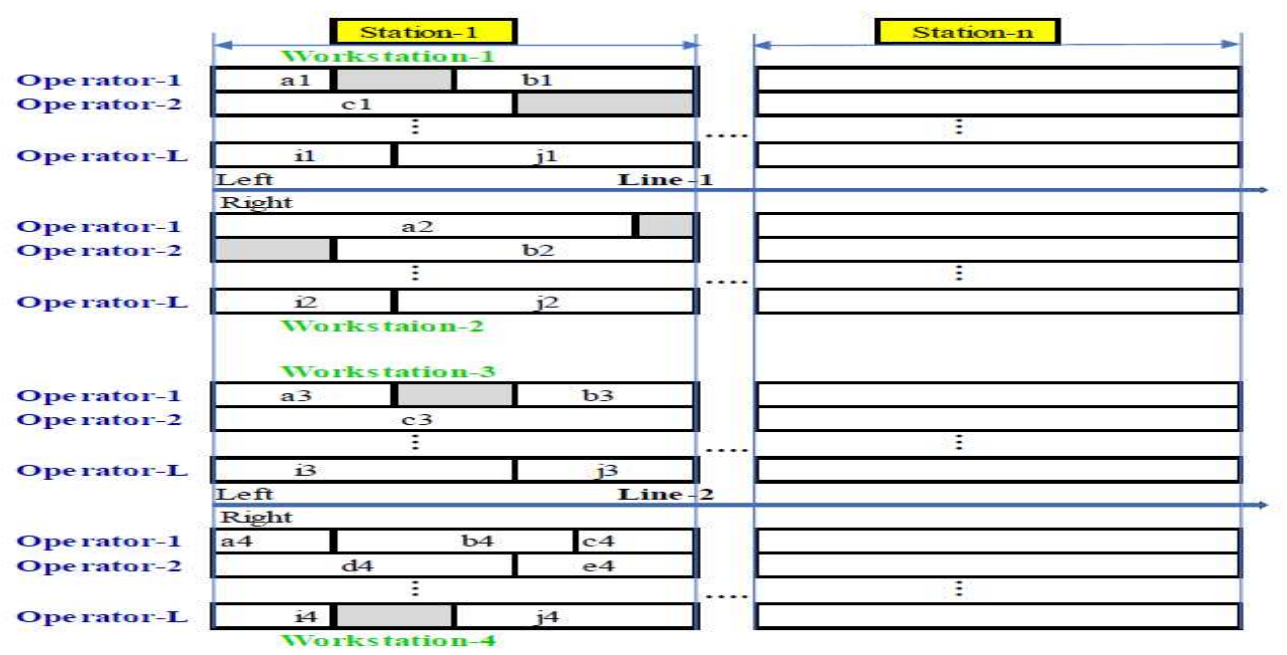

Figure 1: The Structural Illustration of Multi-Manned Parallel Two-Sided Assembly Line

In figure 1 multi-manned assembly line, the product is assembled on two parallel lines and operators can work at the same time on parallel sides of the line. The main aim in a multi-manned assembly line formation is to decrease the line length of the simple assembly line, whereas the total effectiveness of the line remains effective and optimal.

In figure 1 , numbers inside bars indicate task numbers $(\mathrm{a} 1, \mathrm{~b} 1, \mathrm{c} 1 \ldots)$ and lengths of the bars correspond to processing times of tasks. Also, the bars in dark colour indicate idle time of that operator.

\subsection{Assumptions}

The MPTALB problem in this study includes the following assumptions:

- Workers perform tasks in parallel at both the sides of the line

- Some tasks may be required to be performed at one-side of the line, while others may be performed at either side of the line

- The precedence diagrams of different models are known.

- Task times are deterministic and independent of the assigned station. 


\subsection{Notations}

Symbol

$h$ Line index $(h=1 .$.

$i$ Task Index

$\left(i=1, \ldots, n_{h}\right)$

Here $n h=n$

jSide of line

$k$ Station index

$(k=1, \ldots$,

lOperator index

$(l=1, \ldots, \mathrm{L})$

$\mathrm{jd} 0_{\mathrm{hi}}$

Here $\mathrm{jd} 0_{\mathrm{hi}}=\mathrm{jd} 0_{\mathrm{i}}$

jd $1_{\mathrm{hi}}$

Here $\mathrm{jd} 1_{\mathrm{hi}}=\mathrm{jd} 1_{\mathrm{i}}$

$t_{\text {hi }}$

Here $t h i=t i$

$\mathrm{P}_{\mathrm{h}}$

Here $P h=P$

$Z \mathrm{P}$

$Z N$

$Z S$

CT

$\mu \mathrm{A}$

$\beta \mathrm{A}$

\section{Description}

where $H$ represents the total number of lines

where $n_{h}$ represents the total number of tasks on line $h$

for single line problems

$j=\left\{\begin{array}{c}0 \text { indicates left side } \\ 1 \text { indicates right side }\end{array}\right.$

where $K$ represents the total number of utilized stations

where $L$ represents maximum number of operators

Left side direction matrix (task $i$ on line $h$ )

for single line problems

Right side direction matrix (task $i$ on line $h$ )

for single line problems

Processing time of task $i$ on line $h$

for single line problems

Set of precedence relationships in precedence diagram of line $h$

for single line problems

Set of pair of tasks that must be assigned to the same workstation

Set of pair of tasks that cannot be assigned to the same workstation

Set of pairs of tasks that are sharing tool to the same

Common cycle time of the workstations

large number

large number

\subsection{Decision Variable}

Symbol

$\mathrm{Z}_{1}$

$\mathrm{Z}_{2}$

$\mathrm{CW}_{\mathrm{hjk}}$

\section{Description}

Workload on each sub-workstations

Total number of utilized workstations

Capacity of each workstation $\mathrm{x}_{\mathrm{hijkl}}\left\{\begin{array}{c}1 \text { if task } \mathrm{i} \text { is assigned to station } \mathrm{k} \text { on side } \mathrm{j} \text { of line } \mathrm{h} \text { by operator } \mathrm{l} \\ 0 \text { otherwise }\end{array}\right.$

$\mathrm{TWS}_{\mathrm{hjk}}=\mathrm{WS}_{\mathrm{hjk}}\left\{\begin{array}{c}1 \text { if station } \mathrm{k} \text { is utilized on side } \mathrm{j} \text { of line } \mathrm{h} \\ 0 \text { otherwise, }\end{array}\right.$

$\mathrm{TSW}_{\mathrm{hjkl}}=\mathrm{SW}_{\mathrm{hjkl}}\left\{\begin{array}{c}1 \text { if operator l work on side } \mathrm{j} \text { of line } \mathrm{h} \text { and station } \mathrm{k} \\ 0 \text { otherwise }\end{array}\right.$ 


$$
\begin{aligned}
& \min Z=\alpha * \mathrm{Z}_{2}-\mathrm{Z}_{1} \\
& Z_{1}=\sum_{h=1}^{1} \sum_{j=0}^{0} \sum_{k=1}^{K} \sum_{l=1}^{L}\left(\sum_{i=1}^{n_{h}} t_{h i} * X_{h i j k l}\right)^{2} \\
& \mathrm{Z} 2=\sum_{k=1}^{K} W S_{h j k l}
\end{aligned}
$$

The nonlinear objective function in equation (1) represents minimization of $\alpha$ times total number of utilized workstations with maximization of workload so that the number of workstation and idle times can be minimized. Here $Z_{1}$ in equation (2) represents the total number of utilized workstations and $Z_{2}$ in equation (3) represents total workload of the assembly line.

\subsection{Constraints}

$$
\begin{aligned}
& \sum_{k=1}^{K} \sum_{l=1}^{L}\left(J d 0_{h i} * X_{h i 0 k l}+J d 1_{h i} * X_{h i 1 k l}\right)=1 \\
& \sum_{j=0}^{1} \sum_{k=1}^{K} \sum_{l=1}^{L} X_{h i j k l}=1 \forall h=1 . . H ; \forall j \in(0,1) ; \forall i=1 . . n_{h} \\
& \sum_{i=1}^{n_{h}} \sum_{l=1}^{L} t_{h i} * X_{h i j k l}-C T * T W S_{h j k} \leq 0 \\
& \sum_{i=1}^{n_{h}} t_{h i} * X_{h i j k l}-C T * T S W_{h j k l} 0 \\
& \sum_{j \in\{0,1\}} \sum_{l=1}^{L}\left(t_{h i}^{S}+t_{h i}\right) * X_{h i j k} \leq k * c t \\
& \forall h=1 . . H ; \forall j \in(0,1) ; \forall i=1 . . n_{h} ; k=1 . . K ; \forall l=1 . . L \\
& \sum_{i=1}^{n_{h}} X_{h i j k l}-n_{h} * S W_{h j k l} \leq 0 \\
& \sum_{i=1}^{n_{h}} X_{h i j k l}-S W_{h j k l} \geq 0 \\
& \sum_{l=1}^{L} S W_{h j k l}-n_{h} * W S_{h j k} \leq 0 \\
& \sum_{l=1}^{L} S W_{h j k l}-C W_{h j k} \leq 0 \\
& W S_{h j(k+1)}-W S_{h j k} \leq 0 \forall k=1 . . K-1 \\
& \forall h=1 . . H ; \forall j \in(0,1) ; \forall k=1 . . K ; \forall l=1 . . L \\
& X_{h r j k l}-X_{h s j k l}=0 \forall(r, s) \in Z P \\
& X_{h r j k l}+X_{h s j k l} \leq 1 \\
& (r, s) \in Z N ; \forall h=1 . . H ; \forall j \in(0,1) ; \forall k=1 . . K ; \forall l=1 . . L \\
& t_{h r}^{s}+t_{h r}-t_{h s}^{s} \leq 0 \\
& {\left[t_{h s}^{s}-\left\{t_{h r}^{S}+t_{h r}+(k-1) * C T\right\}\right]+\mu *\left\{2-\sum_{j \epsilon(0,1)} \sum_{l=1}^{L}\left(X_{h r j k l}+X_{h s j k l}\right)\right\} \geq 0} \\
& \sum_{j=0}^{1} \sum_{l=1}^{L} X_{h r j k l}-\sum_{j=0}^{1} \sum_{k 1=k}^{K} \sum_{l=1}^{L} X_{h s j(k 1) l} \leq 0 \\
& (r, s) \in p_{h} ; \forall h=1 . . H ; \forall j \in(0,1) ; \forall k=1 . . K ; \forall l=1 . . L
\end{aligned}
$$




$$
\begin{aligned}
& \sum_{l=1}^{L}\left(X_{a r 1 k l}-X_{b s 0 k l}\right) 0 \\
& \sum_{l=1}^{L}\left(X_{a r 0 k l}-X_{b s 1 k l}\right) \leq 1 \\
& (a, r, b, s) \in Z S ; \forall k=1 . . K ; \forall l=1 . . L
\end{aligned}
$$

$$
\left\{\sum_{l=1}^{L}\left(X_{a b(j+1) k l}+X_{r s j k l}\right)-2\right\} * \beta+\gamma_{h j k} *\left(t_{a b}^{S}+t_{a b}-t_{r s}^{S}\right)+\left(1-\gamma_{h j k}\right) *\left(t_{r s}^{S}+t_{r s}-t_{a b}^{S}\right)+(k-1) *
$$

$C T \leq 0$

$$
(a, r, b, s) \in Z S ; \forall k=1 . . K ; \forall j \in(0)
$$

Constraints (4) and (5) ensure that all the tasks are assigned to the workstation and each task is assigned only once. Constraint (6) and (7) ensures that the total workload can't exceed its capacity, means it can't exceed cycle time. Constraint (8) ensures that completion time of any task can't exceed that station time in which the task is assigned. Constraints (9) to (13) ensure utilization of the particular workstation. Some tasks may need to proceed in the same workstation for same specific reason that may originate from work environment or tool(s) requirement (positive zoning constraint). Constraint (14) ensures that those tasks are assigned to the same workstation. Some tasks must be performed in different workstations due to safety rules or processing obligations (negative zoning constraint).

Constraint (15) ensures that those tasks are assigned to different workstations. $Z N$ is the set of pair of tasks that must be assigned to the different workstations for the lineh. Constraint (16) ensures that the starting time of any task is equal to or greater than the completion time of the immediate predecessor of that task in precedence diagram. Constraint (17) ensures that if tasks $r$ and sare assigned to the same station on the same line than starting time of task $s$ is equal to or greater than the summation of completion time of task $r$ and station time of summation of previous situations. Constraint (18) ensures that task $s$ always assigned after task $r$.Constraints (19) and (20) show the tool sharing zone. It ensures that tasks $r$ and sof adjacent lines right side of the line $(h-1)$ with left side of the line $(h)$ are assigned to the same station in the opposite direction. Constraint (21) ensures to remove the clashes from the tasks of shared tools. It means that any two tasks sharing the same tool cannot be assigned at the same time.

\section{SOLUTION APPROACH AND RESULTS}

\subsection{Case Study Problem}

In this section we use $\mathrm{ABC}$ company data (Kucukkoc et al., 2015) to solve multi-manned parallel two-sided assembly line balancing problem (MPTALB) as depicted in Table 2. There are two different products being assembled on two parallel assembly lines (line I and line II) each having the cycle time of 6-time units. Each product consists of 13 and 12 numbers of tasks respectively. Table 2 also indicates task direction (left, right, either) and immediate predecessor, task processing time for both the line I and line II.

Table 2: Data of Industrial Case Study Problem (Kucukkoc et al., 2015)

\begin{tabular}{|c|l|c|c|l|c|c|}
\hline \multicolumn{7}{|c|}{ Line I } \\
Task no & Side & $\begin{array}{c}\text { Processing } \\
\text { Time }\end{array}$ & $\begin{array}{c}\text { Immediate } \\
\text { Predecessors }\end{array}$ & Side & $\begin{array}{c}\text { Processing } \\
\text { Time }\end{array}$ & $\begin{array}{c}\text { Immediate } \\
\text { Predecessors }\end{array}$ \\
\hline 1 & Left & 2 & - & Left & 2 & - \\
\hline 2 & Either & 4 & 1 & Right & 2 & - \\
\hline 3 & Right & 3 & - & Left & 5 & - \\
\hline 4 & Either & 3 & 2 & Either & 1 & 2 \\
\hline 5 & Left & 6 & 1 & Right & 3 & 2 \\
\hline
\end{tabular}




\begin{tabular}{|c|l|l|l|l|l|c|}
\hline \multicolumn{7}{|c|}{ Table 2: Contd., } \\
\hline 6 & Either & 4 & 1 & Either & 3 & 1 \\
\hline 7 & Left & 5 & 4 & Left & 5 & 4 \\
\hline 8 & Either & 4 & 4 & Either & 4 & 5 \\
\hline 9 & Either & 3 & 8 & Left & 4 & 7 \\
\hline 10 & Right & 2 & 3 & Either & 3 & 7,8 \\
\hline 11 & Either & 2 & 10 & Either & 3 & - \\
\hline 12 & Left & 2 & 6 & Left & 2 & 9 \\
\hline 13 & Either & 4 & 11 & - & - & - \\
\hline \multicolumn{7}{|l}{ Total Processing Time 44 } \\
\hline
\end{tabular}

To obtain the solution algorithm of the model was coded in lingo 17.0 solver with the objective of minimizing the total idle time of assembly of two products on line I and line II and runon a 2.1 intelcore i5 computer to test the performance of the proposed algorithm.
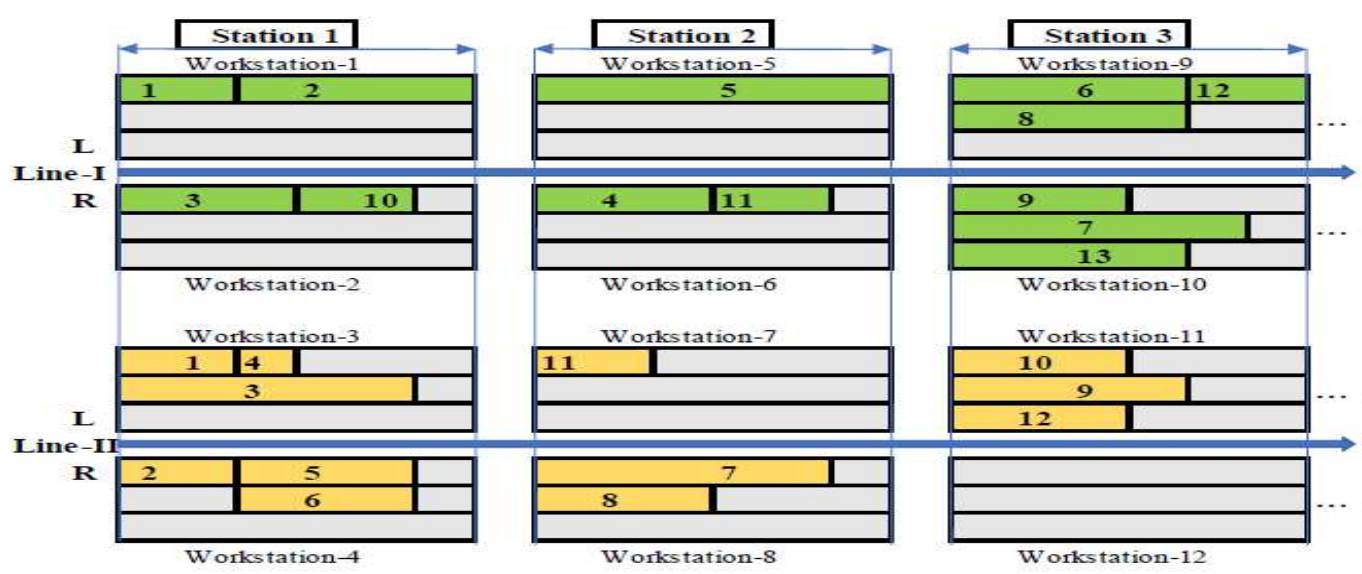

Figure 2: A Possible Balancing Solution for Multi-Manned PTALBP

Figure 2 indicate that the benefit of assigning more than one operator to the required workstations is explained as follows. In this example, workstation 3, workstation 4, workstation 6, workstation 7, workstation 10 and workstation 11 are having more than one working operators. So, the communication between operators is increased and the required space for assembly line setup is decreased.

Theoretical minimum number of workstation $=\left[\frac{\text { Total task time }}{\text { cycle time }}\right]^{+}$

where $[X]+$ denotes the smallest integer greater than or equals to $X$.

Theoretical minimum number of workstation Line $\mathrm{I}=\left[\frac{44}{6}\right]^{+}=8$

Theoretical minimum number of workstation Line II $=\left[\frac{37}{6}\right]^{+}=7$

Therefore, total minimum number of workstations would be $8+7=15$ but in the obtained result, it can be seen that only 11 workstations are utilized. So, the space for extra 4 workstations is saved. 
Table 3: Data for Tool Sharing

\begin{tabular}{|c|c|c|c|}
\hline S.N. & Task no. (Line I) & & ask no.(Line II) \\
\hline 1 & $3 \leftarrow$ & \multirow{5}{*}{ With } & $\longrightarrow 1$ \\
\hline 2 & 10 & & $\longrightarrow 4$ \\
\hline 3 & 11 & & $\longrightarrow 11$ \\
\hline 4 & $\longleftarrow$ & & $\longrightarrow 10$ \\
\hline 5 & 13 & & $\longrightarrow 12$ \\
\hline
\end{tabular}

In this problem common set of resources the expansive tools from tasks of right side of line I are shared with left side of line II or vice versa for saving the cost of purchasing extra tools. In this developed model some set of tasks on any station can share the same type of expansive tools with similar task of any adjacent workstation on another line.

In figure 3 following points can be noted:

- It should be noted here that task-1 of line II workstation-3 cannot be performed with task-3 of line I on workstation-2 and task-4 of line II workstation-3 cannot be performed with task-10 of line I on workstation-2.

- Task-11 of line II workstation-7 cannot be performed with task-11 of line I on workstation-6.

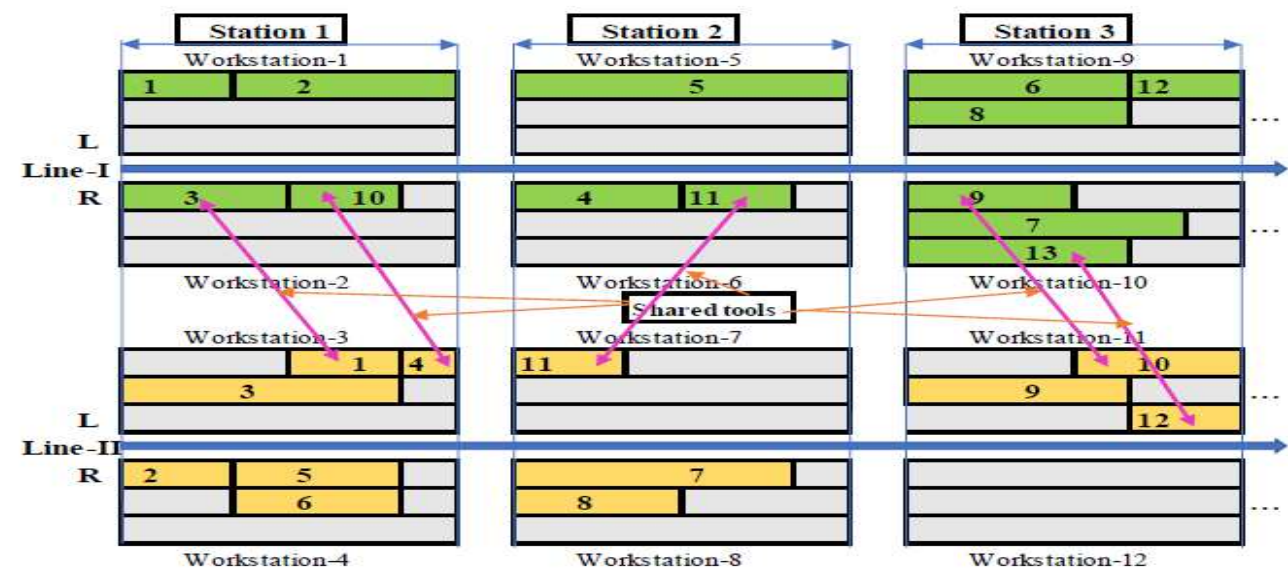

Figure 3: A Possible Balancing Solution for Multi-Manned PTALBP Using Tool Sharing

Table 4: Results of Case Study Problem

\begin{tabular}{|c|c|c|c|c|}
\hline S.N. & Mated Station & Single Workstation & Task Assigned & Tool Share \\
\hline 1 & 1 & $\begin{array}{l}1 \\
2\end{array}$ & $\begin{array}{c}1,2 \\
3,10\end{array}$ & $\begin{array}{l}\text { No } \\
\text { Yes }\end{array}$ \\
\hline & & $\begin{array}{l}3 \\
4\end{array}$ & $\begin{array}{l}1,4,3 \\
2,5,6\end{array}$ & $\begin{array}{l}\text { Yes } \\
\text { No }\end{array}$ \\
\hline 2 & 2 & $\begin{array}{l}1 \\
2\end{array}$ & $\begin{array}{c}5 \\
4,11 \\
\end{array}$ & $\begin{array}{l}\text { No } \\
\text { Yes }\end{array}$ \\
\hline & & $\begin{array}{l}3 \\
4\end{array}$ & $\begin{array}{c}11 \\
7,8\end{array}$ & $\begin{array}{l}\text { Yes } \\
\text { No }\end{array}$ \\
\hline 3 & 3 & $\begin{array}{l}1 \\
2\end{array}$ & $\begin{array}{l}6,12,8 \\
9,7,13 \\
\end{array}$ & $\begin{array}{l}\text { No } \\
\text { Yes }\end{array}$ \\
\hline & & $\begin{array}{l}3 \\
4\end{array}$ & $\begin{array}{c}10,9,12 \\
- \\
\end{array}$ & $\begin{array}{c}\text { Yes } \\
-\end{array}$ \\
\hline \multicolumn{3}{|c|}{ Total No. of Mated Station } & \multicolumn{2}{|l|}{3} \\
\hline \multicolumn{3}{|c|}{ Total No. of Single Station } & \multicolumn{2}{|c|}{11} \\
\hline \multicolumn{3}{|c|}{ Total Tool Share Workstation } & \multicolumn{2}{|l|}{6} \\
\hline
\end{tabular}




\section{CONCLUSIONS AND FUTURE WORK}

In this paper, we presented a new mathematical model for solving the multi-manned parallel two-sided assembly line with maximization of workload so that the number of workstations and idle times can be minimized with the effective tool sharing process.

The solutions obtained by lingo-17 solver for objectives are provided and comparative analysis with theoretical minimum number of mated stations shows that performance on the basis of tool sharing approach provide better results.

In future multi-manned parallel two-sided assembly line can be developed for stochastic approach and metaheuristic, such as tabu search algorithm and simulated annealing algorithm, ant colony optimization algorithm can be applied to solve multi-manned parallel two-sided assembly line balancing problem.

\section{REFERENCES}

1. Dimitriadis, S.G. (2006).Assembly line balancing and group working: A heuristic procedure for workers' groups operating on the same product and workstation. Computer \& Operations Research, 33(9), 2757-2774.

2. Baybars, J.J. (1986).A survey of exact algorithm for the simple assembly line balancing problem. Management Science, 32,909-932.

3. Boysen, N., Fliedner M., Scholl A. (2007). A classification of assembly line balancing problems. Europian Journal of operation Research 183:674-693.

4. Kim YK, Song WS, Kim JH (2009).A mathematical model and a genetic algorithm for two-sided assembly line balancing. Computer Operation Research 36:853-865.

5. Fattahi,P., Roshani, A. and Roshni, A. (2011).A mathematical model and ant colony algorithm for multi-manned assembly line balancing problems. International Journal of Advanced Manufacturing Technology, Vol.53, pp.363-378.

6. Kellegoz, Tand Toklu,B.2012. An efficient branch and bound algorithm for assembly line balancing problems with parallel multi-manned workstations. Computers \& Operations Research 39 (12),3344-3360.

7. Yilmahz, H.(2016).A mathematical model and ant colony algorithm for multi-manned assembly line balancing problem. International Journal of Advanced Manufacturing Technology.

8. Qian, X., Fan, Q.(2011).Solving multi-manned assembly line balancing problem by heuristic-mixed genetic algorithm. International conference on Information Management, Innovation management and Industrial Engineering.Vol.3, pp.320-323.

9. Roshani, A., Roshni, A., Roshni, A., Salehi, M.,(2013).A simulated annealing algorithm for multi-manned assembly line balancing problem. Journal of Manufacturing Syatems.Vol.32, pp.238-247.

10. Kellegoz, T., Toklu, B.(2014).A priority rule-based constructive heuristic and an improvement method for balancing assembly lines with parallel multi-manned workstations. International Journal of Production Research. Vol.53, pp.736-756.

11. Ali, AAM., Negm, A., Bady, M., \& Gamal, M. (2014). Towards An Integrated Tool To Estimate Carbon Emissions From Life Cycle Assessment Of Building Materials In Egypt. IMPACT: IJRET, 2(3), 81-92.

12. Sivasankaran P, Shahabudeen P (2014) Literature review of assembly line balancing problems. International Journal of Advanced Manufacturing Technology73(9):1665-1694

13. Yilmaz, H., YilmazM.(2015). Multi-manned assembly line balancing problem with balanced load density. Assembly Automation. Vol.35, pp.137-142. 
14. Roshani, A., Giglio, D., (2015). A Mathematical Programming Formulation for Cost-oriented Multi-manned Assembly Line Balancing Problem. IFAC-Papers On Line 48(3),2293-2298.

15. Roshani, A.Giglio, D., (2015). A simulated annealing approach for multi-manned assembly line balancing problem type II. IFAC-Papers on Line 48(3), 2299-2304.

16. KucukkocI., and D. Z. Zhang. (2015). A mathematical model and genetic algorithm-based approach for parallel two-sided assembly line balancing problem. Production Planning \& Control: The Management of Operations, 26:11, 874-894

17. Kellegoz, T.(2016). Assembly line balancing problems with multi-manned stations: a new mathematical formulation and Gantt based heuristic method. Annals of Operation Research,1-28.

18. Chikalthankar, S., Nandedkar, V., \& Borde, S. Influence of machining parameters on electric discharge machining of WPS tool steels-An experimental Investigation.

19. Chen, Y. (2017). A hybrid algorithm for allocating tasks, operators and workstations in multi-manned assembly lines. Journal of Manufacturing Systems.Vol.42, pp.196-209.

20. Yilmaz, H. \& Yilmaz, (2017) Note to: a mathematical model and ant colony algorithm for multi-manned assembly line balancing problem International Journal of Advanced Manufacturing Technology 89: 1935.

21. Chen, Y., Cheng. C, Li.J.(2018). Resource-constrained assembly line balancing problems with multi- manned Workstations Journal of Manufacturing Systems. Vol.48(2018) pp.107-119 